\title{
Public Health Programs and Cardiovascular Diseases
}

\author{
Paolo Blanco Villela ${ }^{(10}$ and Larissa Franco de Andrade ${ }^{1(0)}$ \\ Universidade Federal do Rio de Janeiro, ${ }^{\prime}$ Rio de Janeiro, RJ - Brazil \\ Editorial referring to the article: Stroke and Myocardial Infarction: Effects of the "Hiperdia" and "Mais Médicos" Programs on the \\ Hospitalizations Trends in Brazil.
}

For decades, cardiovascular diseases, mainly coronary artery disease and stroke, have been the main cause of death in Brazil. In 2017, they accounted for 27.3\% of all deaths in the country, with an age-standardized mortality rate of 178 per 100,000 inhabitants. ${ }^{1}$ In the same year, cerebrovascular diseases had an age-standardized mortality rate of 80 per 100,000 inhabitants. ${ }^{1}$ With respect to the burden of cardiovascular diseases, the number are even more concerning, with 1,602.4 disability-adjusted life years (DALYs) per 100,000 inhabitants for coronary disease and 1,145.3 DALYs per 100,000 inhabitants for stroke. ${ }^{1}$

Although these numbers represent a decrease when compared with numbers in the year of 1990, the control of cardiovascular risk factors is clearly important. In this regard, in addition to the traditional risk factors, socioeconomical factors are known to play an important role in the development of these diseases. Investigators of the Prospective Urban Rural Epidemiologic (PURE) study ${ }^{2}$ evaluated socioeconomic status and educational attainment in adults aged between 35 and 70 years from 367 urban and 302 rural communities in 20 countries (five low-income countries, 11 middle-income and five low-income countries), with a total of 164,169 participants. The authors concluded that people with a lower level of education had higher mortality rates from cardiovascular events in all the countries. ${ }^{2}$ However, the authors discuss that these findings may be explained not only by the higher prevalence of risk factors, but also by the lower access to secondary prevention and medical management of chronic diseases such as hypertension

\section{Keywords}

Cardiovascular Diseases; Public Health; Myocardial Infarction; Stroke; Hospitalization; Socioeconomic Factors. and diabetes mellitus compared with people with higher level of education. ${ }^{2}$ This is in line with the study by Schultz et al., ${ }^{3}$ who demonstrated that even in high-income countries, factors like employment status, educational attainment, income level, and neighborhood socioeconomic factors are related to cardiovascular diseases. ${ }^{3}$ Thus, the authors consider the access to health services as part of a high-quality health care of low socioeconomic status populations. ${ }^{3}$ Therefore, it is possible to infer that, compared with absolute income, inequality levels are more stronger determinants of cardiovascular outcomes.

Several methods have been proposed to measure the degree of inequality, including the Gini coefficient, ${ }^{4}$ and indirect indicators of income. One of these is the percentage of health care plan members ${ }^{5}$ considering that individual health care plans are expensive and require regular monthly income, and collective plans require an employment bond.

Today, according to the World Bank, Brazil is classified as an upper-middle-income country, ${ }^{6}$ where $24 \%$ of population are covered by supplemental health insurance plans. Most of them are from higher income areas like the states of Sao Paulo, Rio de Janeiro and Rio Grande do Sul, and lower percentages of beneficiaries are found in states of the north and northeast Brazil, like Amapa, Tocantis and Maranhao. ${ }^{7}$ A previous study showed an inverse relationship between health care coverage and mortality from cerebrovascular and hypertensive diseases. ${ }^{5}$

Evidently, to be a member of a supplemental health plan does not guarantee access to healthcare, but when used as an indirect marker of income, it reflects the huge degree of health inequalities observed in the country. Therefore, nationwide public health programs that include more vulnerable areas are of paramount importance, as reported by Santos et al., 
in the current issue of the International Journal of Cardiovascular Sciences. The authors evaluated the impact of the "Hiperdia" and "Mais Médicos" programs on hospitalizations for acute myocardial infarction and stroke between 1998 and 2018.

Using data from the hospital information system of the Department of Informatics of the Brazilian national unified health system (SIH-DATASUS), Santos et al. ${ }^{8}$ evaluated the time course of the number of hospitalizations by sex and federated states during the mentioned period. ${ }^{8}$ Except for Amapa, where hospitalization rates had a stable pattern over time, rates of hospitalization for acute myocardial infarction increased in all federated states. On the other hand, the hospitalizations for stroke decreased in all federated states, except for Amazonas and Roraima. ${ }^{8}$

The authors also showed that the "Mais Médicos" program, and specially the "Hiperdia" program contributed to the reduction in hospitalizations for stroke.

\section{References}

1. Oliveira GMM, Brant LCC, Polanczyk CA, Biolo A, Nascimento BR, Malta DC, et al. Estatística cardiovascular Brasil 2020. Arq Bras Cardiol. 2020; 115(3):308-439. DOI: 10.36660/abc.20200812.

2. Rosengren A, Smyth A, Rangarajan S, Ramasundarahettige C, Bangdiwala SI, AlHabib KF, et al. Socioeconomic status and risk of cardiovascular disease in 20 low-income, middle-income, and high-income countries: the Prospective Urban Rural Epidemiologic (PURE) study. Lancet Glob Health. 2019; 7(6):e748-60. DOI: 10.1016/ S2214-109X(19)30045-2.

3. Schultz WM, Kelli HM, Lisko JC,Varghese T, Shen J, Sandesara P, et al. Socioeconomic Status and Cardiovascular Outcomes - Challenges and Interventions. Circulation. 2018;137(20):2166-78. DOI: 10.1161/ CIRCULATIONAHA.117.029652

4. Base de dados macroeconômicos, financeiros, e regionais do Brasil. IPEA Data. [Internet] [Acesso em julho ,2021] Disponível em https://www.ipea.
However, although the same effect was not observed on the rate of hospitalizations for acute myocardial infarction, these programs attenuated the progression in the number of cases. In addition, the Brazilian National Program for Improving Primary Care Access and Quality (PMAQ) was evaluated for its influence on the trends of hospitalizations for stroke and myocardial infarction. However, this was an organizational flow and capacitation program, which may have limited its ability to demonstrate an impact on the outcomes during the study period. ${ }^{8}$

Finally, the findings reported by Santos et al. should encourage the development and expansion of primary health care programs in the country, mainly in more vulnerable areas. Promoting an equal access to healthcare should be considered an essential condition for cardiovascular risk reduction and occur in parallel with measurements aimed at improving quality of life and reducing social disparities. gov.br/desafios/index.php?option=com_content\&view=article\&id=2048: catid $=28 \&$ Itemid $=23$

5. Villela PB, Klein CH, Oliveira GMM. Socioeconomic factors and mortality due to cerebrovascular and hypertensive disease in Brazil. Rev Port Cardiol. 2019;38(3):205-12. DOI: doi.org/10.1016/j.repc.2018.07.007.

6. World Bank Open Data. Open data Supports Public, Oversight of Governments. [Internet] [Acesso em julho, 2021]. Disponível em https:// data.worldbank.org/country/brazil

7. Agência Nacional de Saúde Suplementar. (ANSS) Sistema de gestão para planos de saude. [Internet] Acesso em julho, 2021] Disponível em [https:// www.gov.br/ans/pt-br/acesso-a-informacao/perfil-do-setor/dados-gerais

8. Santos JM, Martinez ABR, Silva EJ, Souza GRS, Lopes JK. Stroke and Myocardial Infarction: Effects of the "Hiperdia" and "Mais Médicos" Programs on the Hospitalizations Trends in Brazil. Int J Cardiovasc Sci. 2021; 34(5Supl.1):44-52. DOI: 10.36660/ijcs.20200270. 